\title{
Role of mycology in accurate diagnosis of various fungal aetiologies in rhino/orbital diseases: 'needle in a haystack'
}

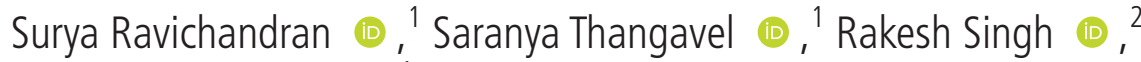 \\ Sivaraman Ganesan
}

'ENT, Jawaharlal Institute of Postgraduate Medical Education and Research, Puducherry, India ${ }^{2}$ Microbiology, Jawaharlal Institute of Post Graduate Medical Education and Research, Puducherry, Pondicherry, India

Correspondence to Dr Saranya Thangavel; softsaran.nrp@gmail.com

Accepted 29 April 2021
D Check for updates

(c) BMJ Publishing Group Limited 2021. No commercial re-use. See rights and permissions. Published by BMJ.

To cite: Ravichandran $S$, Thangavel $S$, Singh $R$, et al. BMJ Case Rep

2021:14:e242684 doi:10.1136/bcr-2021242684

\section{DESCRIPTION}

A 37-year-old man with no known comorbidities presented to our department with complaints of left eye proptosis and diminution of vision for 1 month and left facial swelling for the past 2 years. He underwent left-sided nasal surgery thricefunctional endoscopic sinus surgery (FESS) in 2018 , followed by revision FESS in 2019, followed by Caldwell Luc procedure in 2020. In 2018, the biopsy report was caseating granulomatous lesion, and so he was started on antitubercular drugs for 6 months, but there was no response to treatment. In 2020, it was reported as a fungal granuloma. He was not started on antifungal drugs despite the persistence of symptoms. On external examination, left diffuse facial swelling with depression at nasal ala and left eye proptosis with reduced infraorbital sensations (figure 1A,B). Diagnostic nasal endoscopy showed left vestibular stenosis with status postoperative FESS with no evident growth or mass inside the sinuses. Visual acuity was 5/60 on right and hand movements close to face on the left with abaxial proptosis, non-reacting pupils, corneal ulcer with restriction of extraocular movements in all sides. Contrast-enhanced CT (CECT) of the nose and paranasal sinuses showed left lobulated hyper dense non enhancing lesion with extensive destruction involving the orbit, maxillary, bilateral sphenoid and ethmoid sinuses and extending into intracranial and left infratemporal fossa with encasement of bilateral cavernous part of Internal Carotid Artery (ICA) (figure 2A,B).

Because of its extensive involvement in the skin and subcutaneous tissues, phaeohypomycosis was considered the diagnosis. Fine-needle aspiration cytology from the left facial swelling was reported as a possibility of aspergillosis with epithelioid granuloma with septate, fungal hyphae. Periodic acid-Schiff and Gomori methenamine silver were positive for the fungus. Fungal culture and staining were suggestive of Aspergillus flavus (figures 3 and 4). When the culture report was awaited, the patient was started on injection liposomal amphotericin B with the cumulative dosage of $1800 \mathrm{mg}$. The patient was started on an injection voriconazole $200 \mathrm{mg}$ stat dose, followed by tablet $200 \mathrm{mg}$. The patient responded very well, and the left facial swelling and proptosis had reduced (figure 1C,D) with repeat CECT showing resolution of disease (figure 2C,D).

A maxillary sinus aspirate material and a conjunctival swab sample were collected and sent to the

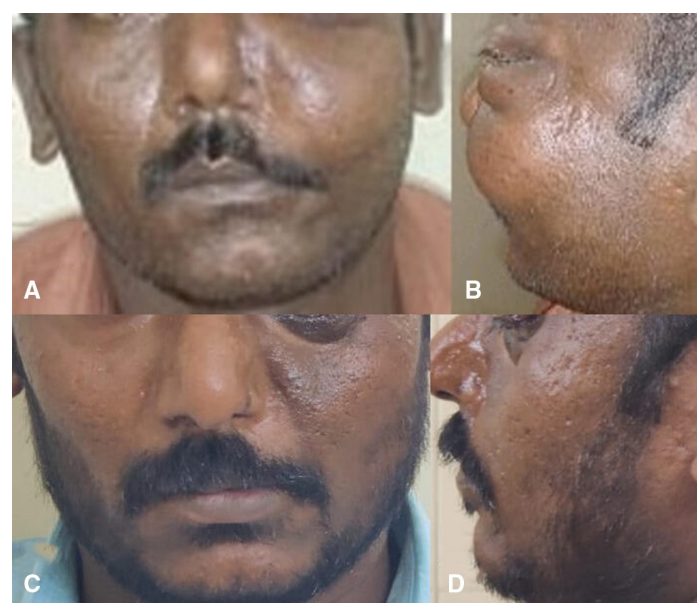

Figure 1 Showing external facial appearance. (A, B) pretreatment with left facial swelling with left eye proptosis and chemosis. (C, D): post-treatment with completely reduced facial swelling and proptosis.

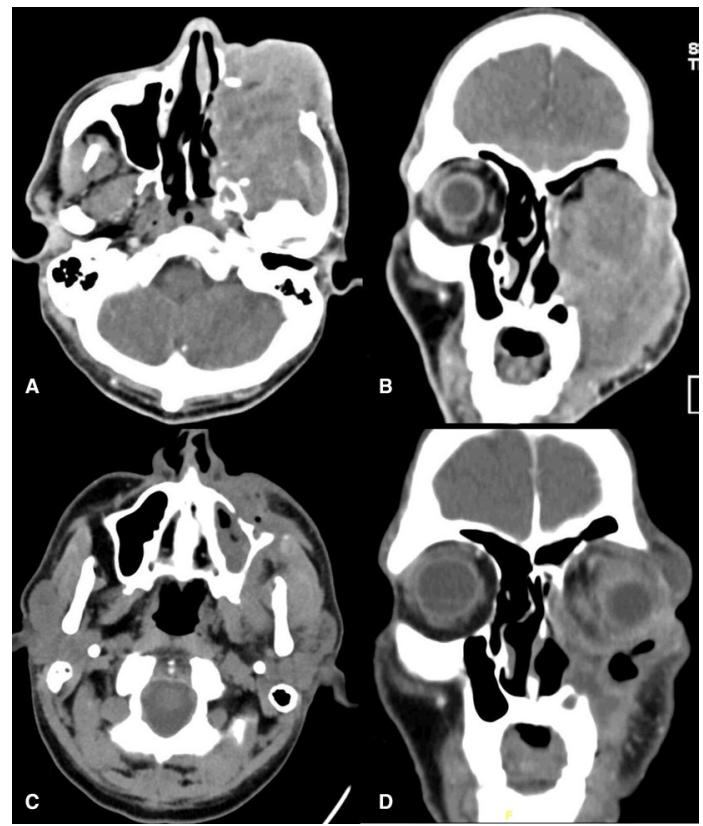

Figure 2 CECT nose and PNS showing. (A, B):

Pretreatment left hyper dense non-enhancing lesion with maxillary swelling in axial view(A) and coronal view (B). (C, D) Post-treatment resolution of disease in axial (C) and coronal views (D). CECT, contrast-enhanced CT. 


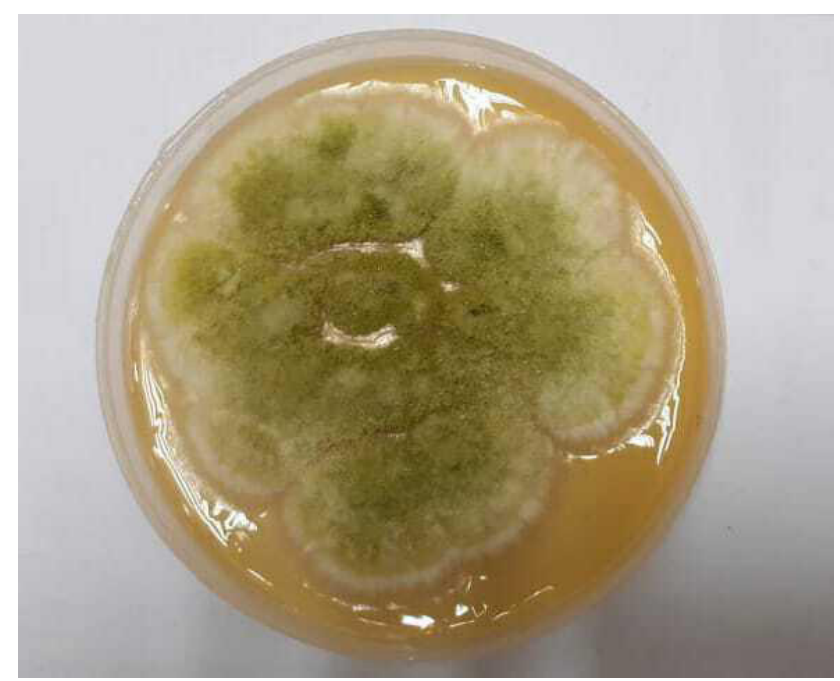

Figure 3 SDA growing Aspergillus flavus with the characteristic yellow-green to an olive colony with a white border and a velvety or cottony texture. SDA, sabouraud dextrose agar.

department of microbiology. Ten per cent potassium hydroxide $(\mathrm{KOH})$ mount was prepared from sinus aspirate material which was negative. The conjunctival swab was inoculated into sabouraud dextrose agar (SDA) culture plate. The sinus aspirate sample was inoculated into multiple tubes of SDA. Inoculated culture media were incubated at $25^{\circ} \mathrm{C}$. A yellow-green, velvety and powdery growth with a white margin was observed within 5 days of incubation. No pigmentation was seen on the reverse side of the fungal growth. Lactophenol cotton blue (LPCB) tease mount was prepared and observed under the microscope. Hyaline septate hyphae were observed with spiny conidiophore, which was ending in the vesicle. Phialides and metulae entirely covered the vesicle. Chains of conidia were seen arising from metulae, which was morphologically suggestive of $A$. flavus species complex.

A. flavus has a conidiophore bearing vesicle with a typical biseriate structure with metulae and phialide. The conidiophore also has this rough or gently spiked texture, particularly at the apex (where it meets the vesicle), a diagnostic feature of A. flavus. Phialides radiate from the vesicle in all directions.

A sample taken from the nasal cavity - nasal crust—is sent for fungal staining and fungal culture.

\section{$\mathrm{KOH}$ examination}

$\mathrm{KOH}(10 \%)$ lyses the fungal cell wall's protein content and reveals fungal elements. After lysis, it is examined under light
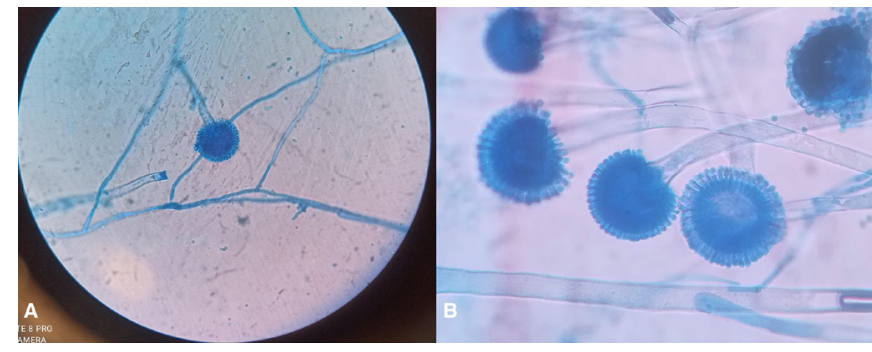

Figure 4 LPCB staining showing thin long conidiophore and vesicle at the apex bearing phialides radiating from the entirety of the vesicle, characteristic of Aspergillus flavus (A) $\times 40$ and $(B) \times 100$. LPCB, lactophenol cotton blue.

\section{Patient's perspective}

I was taking treatment for my condition for the past 2 years. I feel delighted after my swelling got reduced with treatment here. Now I am on regular follow-up and feeling happy.

\section{Learning points}

- Phaeohypomycosis means the condition of fungi with dark hyphae and is very rare in immunocompetent individuals.

- The high index of suspicion of aspergillosis should be kept in mind in immunocompetent individuals and confirmed with a fungal culture.

- Aspergillus grows from haematogenous lesions in tissues in a radial fashion, like wheel spokes, with the hyphae appearing nearly parallel to one another.

- The parallel arrangement of aspergillus is absent if the tissue is not intact or if the specimen is more liquid.

microscopy at $10-40 \times$ magnification. In this case, thin hyaline septate hyphae with acute-angled branching were noted suggestive of Aspergillosis.

\section{Fungal culture}

Aside from the fact that fungal culture helps in identifying the species of Aspergillus infection, it also helps in identifying the resistance to antifungal therapy; for example, Aspergillus terreus and Aspergillus nidulans are found to have an inherent resistance to amphotericin-b. ${ }^{1-3}$ All medically important fungi samples must be sent in a sealed, leak-proof, sterile container marked with a biohazard sticker to comply with occupational safety and health administration safety standards. ${ }^{4}$ It should be transported within 2 hours; otherwise, it should be stored at $4^{\circ} \mathrm{C}$.

The sample after $\mathrm{KOH}$ staining is inoculated in SDA medium either in plates or tubes. SDA is preferred as it is more efficient and has been found a high detection rate for a wide range of fungi. ${ }^{5}$ After incubating at $25^{\circ} \mathrm{C}$ for $3-4$ days, an olive green coloured growth with velvety or cottony texture with clear margins will be noted in the medium.

\section{Fungal staining}

On examining, this cultured growth under light microscopy after LPCB staining, thin septate hyphae with conidiophores bearing vesicle at its apex will be noted. The wall of the conidiophores is rough or spiny, especially below the vesicle. Uniserate or biserate phialides are formed, pointing out in all directions covering the entire vesicle.

Acknowledgements I would like to thank Professor Dr. Sunil Kumar Saxena for supporting in submitting this article and Dr. Mukundan for providing valuable information regarding mycological data.

Contributors SR: conception and design, acquisition of data or analysis and interpretation of data. ST: drafting the article or revising it critically for important intellectual content. SG and RS: final approval of the version published. ST: agreement to be accountable for the article and to ensure that all questions regarding the accuracy or integrity of the article are investigated and resolved.

Funding The authors have not declared a specific grant for this research from any funding agency in the public, commercial or not-for-profit sectors.

Competing interests None declared.

Patient consent for publication Obtained.

Provenance and peer review Not commissioned; externally peer reviewed. 


\section{ORCID iDs}

Surya Ravichandran http://orcid.org/0000-0002-4579-9835

Saranya Thangavel http://orcid.org/0000-0001-6954-1364

Rakesh Singh http://orcid.org/0000-0002-2213-3993

Sivaraman Ganesan http://orcid.org/0000-0002-7065-0258

\section{REFERENCES}

1 Walsh TJ, Petraitis V, Petraitiene R, et al. Experimental pulmonary aspergillosis due to Aspergillus terreus: pathogenesis and treatment of an emerging fungal pathogen resistant to amphotericin B. J Infect Dis 2003;188:305-19.
2 Kontoyiannis DP, Lewis RE, May GS, et al. Aspergillus nidulans is frequently resistant to amphotericin B. Mycoses 2002;45:406-7.

3 Van Der Linden JWM, Warris A, Verweij PE. Aspergillus species intrinsically resistant to antifungal agents. Med Mycol 2011:49:S82-9.

4 Miller JM, Astles R, Baszler T, et al. Guidelines for safe work practices in human and animal medical diagnostic laboratories. MMWR Surveill Summ 2012:6:13.

5 Gebala B, Sandle T. Comparison of different fungal agar for the environmental monitoring of pharmaceutical-grade cleanrooms. PDA J Pharm Sci Technol 2013:67:621-33.

Copyright 2021 BMJ Publishing Group. All rights reserved. For permission to reuse any of this content visit

https://www.bmj.com/company/products-services/rights-and-licensing/permissions/

BMJ Case Report Fellows may re-use this article for personal use and teaching without any further permission.

Become a Fellow of BMJ Case Reports today and you can:

- Submit as many cases as you like

Enjoy fast sympathetic peer review and rapid publication of accepted articles

- Access all the published articles

Re-use any of the published material for personal use and teaching without further permission

Customer Service

If you have any further queries about your subscription, please contact our customer services team on +44 (0) 2071111105 or via email at support@bmj.com.

Visit casereports.bmj.com for more articles like this and to become a Fellow 